Original Article

\title{
COMPARATIVE STUDY BETWEEN THE EFFECT OF HISTAMINE RECEPTOR ANTAGONISTS OF TYPE II (FAMOTIDINE) AND PROTON PUMP INHIBITORS (OMEPRAZOLE) ON THE EFFICACY OF CALCIUM CARBONATE AS PHOSPHATE BINDER IN HAEMODIALYSIS PATIENT
}

\author{
HOSSAM ABOELYAZEED ${ }^{1}$, SAHAR El-HAGGAR ${ }^{2}$, KAMAL OKASHA ${ }^{3}$ \\ 1B. Sc. Pharmaceutical Sciences, Faculty of Pharmacy, Tanta University, Egypt, ${ }^{2}$ Assistant Professor of Clinical Pharmacy, Faculty of \\ Pharmacy, Tanta University, Egypt, ${ }^{3}$ Professor of Internal Medicine and Nephrology, Faculty of Medicine, Tanta University, Egypt \\ Email: hossam_pharmacy@hotmail.com
}

Received: 06 Apr 2016 Revised and Accepted: 19 Jun 2017

\section{ABSTRACT}

Objective: The purpose of this study was to compare the effect of famotidine versus omeprazole on the efficacy of calcium carbonate as a phosphate binder in the hemodialysis patient.

Methods: From February 2014 to June 2014 a total number of 64 patients of both sexes were recruited from the department of renal dialysis, Tanta University Hospital, Egypt. Patients categorized into 3 groups. Group I (control group) consisted of 20 Patients (10) females and (10) males take calcium carbonate $\left(\mathrm{Caco}_{3}\right)(2.5-4 \mathrm{~g} / \mathrm{d})$ only, Group II consisted of 21 Patients (13) females and (8) males take the same dose of caco 3 with famotidine $10 \mathrm{mg} / \mathrm{d}$ and Group III consisted of 23 Patients (8) females and (15) male take the same dose caco 3 with omeprazole $20 \mathrm{mg} / \mathrm{d}$.

Results: All data are expressed as the mean \pm SD. Group II showed a significant increase $(p<0.05)$ in serum phosphorus at $3^{\text {rd }}$ mo with significant decreased $(p<0.05)$ in serum calcium comparing with pre-treatment. Group III showed no significant change $(p>0.05)$ in serum calcium, phosphorus and parathyroid hormone (PTH) comparing with pre-treatment. Both groups (II and III) showed a significant decrease in alkaline phosphatase (ALP) ( $p<0.05$ ).

Conclusion: Co-administration of famotidine with calcium carbonate aggravates hyperphosphatemia and this may increase the incidence of complications. The efficacy of calcium carbonate as a phosphate binder was not affected by co-administration of omeprazole.

Keywords: Famotidine, Hyperphosphatemia, Haemodialysis, Omeprazole

(C) 2017 The Authors. Published by Innovare Academic Sciences Pvt Ltd. This is an open access article under the CC BY license (http://creativecommons.org/licenses/by/4.0/) DOI: http://dx.doi.org/10.22159/ijpps.2017v9i8.12072

\section{INTRODUCTION}

End-stage renal disease (ESRD) is the complete or almost complete failure of the kidneys to work. Kidneys are no longer able to work at a level needed for $d$ to $d$ life. The most common causes of ESRD are diabetes and hypertension. ESRD detected as an increase in serum creatinine or proteinuria also, many signs and symptoms appear on the patient. Dialysis or kidney transplantation is the only treatment for this condition

Hyperphosphatemia is one of the main complications in ESRD patient. It is an electrolyte disturbance in which there is an abnormally elevated level of phosphate in the blood $(5 \mathrm{mg} / \mathrm{dL}$ in adults and $7 \mathrm{mg} / \mathrm{dL}$ in children or adolescents) caused by many causes include chronic kidney disease. It is associated with high mortality risk [1]. Typically, most patients with hyperphosphatemia are asymptomatic. However, patients occasionally report hypocalcemic symptoms. More commonly, patients report symptoms related to the underlying cause of hyperphosphatemia. Serious effect on the person's nervous and cardiovascular system $[2,3]$ may occur. Complications include ectopic calcification [4, 5] secondary hyperparathyroidism [4] and renal osteodystrophy.

Treatment includes a diet low in phosphate and use of phosphate binder including calcium-containing phosphate binder which most commonly used [6]. The primary goal of treatment is to reduce serum phosphorus to normal levels in patients with stage 3-5 chronic renal failure (CRF) and to $5.5 \mathrm{mg} / \mathrm{dL}$ or less in patients with stage 5D CRF [7]

In chronic renal failure and particularly in ESRD, upper gastrointestinal bleeding from gastroduodenal ulcers, erosive gastritis or esophagitis by gastroesophageal reflux is frequent. The use of inhibitors of gastric acid secretion is the base for the preventive or curative treatment of these complications, even if the gastric hyperacidity induced by hypergastrinemia due to renal failure is not constant. Patients on dialysis usually have fragile gastrointestinal tract and gastrointestinal symptoms [8]. These patients usually use proton pump inhibitor or H2-receptor antagonist.

Metallic phosphate binders require acidity to dissociate to the free metallic ion and bind phosphorus. Altered gastric acidity may, therefore, influence phosphate-binding efficacy [9].

The objective of this study was to compare the effect of famotidine versus Omeprazole on the efficacy of calcium carbonate as a phosphate binder in the hemodialysis patient.

\section{MATERIALS AND METHODS}

Study design

Randomized, prospective, controlled, open-labeled study was used included sixty-four Patients of both sexes from the department of renal dialysis, Tanta University Hospital, Egypt.

This study was approved by the Research Ethics Committee of Faculty of Pharmacy-Tanta University (REC-FPTU). Written consents from all patients enrolled in the study were obtained. From patient history, these patients were categorized into three groups; Group I (control group) consisted of 20 Patients (10) females and (10) males take $\mathrm{CaCO}_{3}$ only, Group II consisted of 21 Patients (13) females and (8) males take the same dose of $\mathrm{Caco}_{3}$ with famotidine $10 \mathrm{mg} / \mathrm{d}$ and Group III consisted of 23 Patients (8) females and (15) male take the same dose $\mathrm{Caco}_{3}$ with omeprazole $20 \mathrm{mg} / \mathrm{d}$. All patients received their medications for $4 \mathrm{mo}$.

Blood samples were collected before the study and then monthly during the study for four mo during hemodialysis sessions for serum phosphate, calcium, ALP and PTH levels. There is no change in dialysis schedule during the study period (Time, frequency, dialysate calcium content or filter). 


\section{Inclusion criteria}

- ESRD patients treated with calcium carbonate alone as a phosphate binder.

- The presence of ESRD during dialysis periods with phosphorus levels $>5.5 \mathrm{mg} / \mathrm{dL}$.

- Patients should be on a diet low in phosphorus.

- Receiving three times weekly hemodialysis more than 6 mo.

- Male and female patients will be included.

\section{Exclusion criteria}

The patient will be excluded if there is evidence of:

- Active peptic ulcer, recent gastrointestinal bleeding or major oesophagal reflux.

- Severe hyperparathyroidism.

- Hypercalcemia.

- Treatment with vitamin D analogs.

- Smoking

\section{Specifications of drugs}

Calcium carbonate manufactured by the elnasr pharmaceutical company, abozabal, Cairo, Egypt.

Famotidine manufactured by amoun pharmaceutical company, elobour city, Cairo, Egypt.

Omeprazole manufactured by elfaronia pharmaceutical company, masr elgededa, Cairo, Egypt.

\section{Laboratory analyses}

\section{Sample collection}

Blood sampling was performed at the start of the study and then monthly for four mo during the hemodialysis sessions. Five $\mathrm{ml}$ blood was collected from the antecubital vein into sterile tubes, then centrifugated immediately with $3000 \mathrm{x}$ g for $10 \mathrm{~min}$ to separate sera, then biochemical analyses were done for serum phosphate, calcium, alkaline phosphates and PTH levels.

\section{Assay}

1-Serum calcium level was measured on Microlab 200 (MERCK Instrument Inc.; Scientific Instrument Division, Germany) by using kits supplied by STANBIO laboratories (USA). Using a colorimetric assay according to the method of Stern and Lewis., 1957; Sarkar and Chauhan., 1967 [10,11].

2-Inorganic serum phosphorus was measured on Microlab 200 (MERCK Instrument Inc.; Scientific Instrument Division, Germany) by using kits supplied by STANBIO laboratories (USA). Using a spectrophotometric assay according to the method of Fiske and Subbarow., 1925; Goodwin, 1970 [12, 13].

3-Serum ALP was measured on Microlab 200 (MERCK Instrument Inc.; Scientific Instrument Division, Germany) by using kits supplied by STANBIO laboratories (USA). Using a kinetic method according to the method of Fujita 1939; Bowers and McCOMBR., $1966[14,15]$.

4-Serum PTH was assayed on VIDAS Multiparametric immune analyzer (Biomerieux Inc.; Scientific Instrument Division, Marcy l'Etoile, France) by using VIDAS kit supplied by BIOMERIEUX laboratories (France) using a double sandwich technique according to the method of Armitage; 1986; Kao et al., 1992 [16, 17].

\section{Statistical analysis}

All data are expressed as the mean \pm SD. The mean values of each group compared with the pretreatment mean values using paired student t-test and the mean values of the three groups compared using one-way ANOVA followed by Tukey's test using a level of significance of ${ }^{*} p<0.05$. Statistical significance will be carried out using SPSS Software for windows version 20 (2011).

\section{RESULTS}

A total number of 64 patients of both sexes were recruited from the department of renal dialysis, Tanta University Hospital, Egypt. Patients categorized into 3 groups. Group I (control group) consisted of 20 Patients (10) females and (10) males take $\mathrm{Caco}_{3}$ only, Group II consisted of 21 Patients (13) females and (8) males take the same dose of $\mathrm{Caco}_{3}$ with famotidine $10 \mathrm{mg} / \mathrm{d}$ and Group III consisted of 23 Patients (8) females and (15) male take the same dose $\mathrm{CaCO}_{3}$ with omeprazole $20 \mathrm{mg} / \mathrm{d}$.

The demographic characteristics were shown in table 1. As seen from table 1 , no significant differences between the three studied groups in age, sex, and duration of dialysis ( $p>0.05)$.

The biochemical of group I throughout the study are shown in table 2. Paired student $t$-test was carried out for each parameter between the baseline results and the results of each mo post treatment. There were no significant changes in the four parameters throughout the study ( $p>0.05)$.

Table 1: It shows the demographic characteristics of the three studied groups

\begin{tabular}{|c|c|c|c|}
\hline Characteristics & $\begin{array}{l}\text { Group I } \\
\text { (control group) }(\mathrm{N}=20)\end{array}$ & $\begin{array}{l}\text { Group II } \\
\text { (famotidine } / \text { caco }_{3} \text { group) }(\mathrm{N}=21)\end{array}$ & $\begin{array}{l}\text { Group III } \\
\left.\text { (omeprazole } / \text { caco }_{3} \text { group }\right)(\mathrm{N}=23)\end{array}$ \\
\hline Age & $52.71 \pm 9.61$ & $47.19 \pm 12.1$ & $46.56 \pm 10.2$ \\
\hline \multirow[t]{2}{*}{ Sex } & 10 & 8 & 15 \\
\hline & 10 & 13 & 8 \\
\hline $\begin{array}{l}\text { Duration of dialysis } \\
\text { (mo) }\end{array}$ & $92.8 \pm 22.6$ & $94.2 \pm 20.71$ & $92.08 \pm 23.4$ \\
\hline
\end{tabular}

-Data are represented as mean $\pm S D,-N$, Number of patients

Table 2: It shows Group I (control group) biochemicals throughout the study

\begin{tabular}{lllc}
\hline Parameters & Phosphorus level (mg/dl) & Calcium level (mg/d) & ALP level (mg/dl) \\
\cline { 1 - 3 } Interval & & $9.71+0.57$ & $96.88+33.4$ \\
\cline { 1 - 2 } Baseline & $5.69+0.87$ & $8.04+0.99$ & $89.41+27.1$ \\
$1^{\text {stmo post treatment }}$ & $5.75+0.84$ & $7.85+0.75$ & $88.92+12.37$ \\
$2^{\text {nd }}$ mo post treatment & $5.80+0.63$ & $8.31+0.74$ & $86.52+8.36$ \\
$3^{\text {rd }}$ mo post treatment & $5.99+0.89$ & $8.36+0.69$ & $151.8+49.2$ \\
$4^{\text {th }}$ mo post treatment & $6.03+0.69$ & $161+38.2$ & $168+44.6$ \\
\hline
\end{tabular}


The biochemical of group II throughout the study are shown in table 3. Paired student $t$-test was carried out for each parameter between the baseline results and results of each mo post treatment shown a significant increase in serum phosphorus level from the baseline occurred in $3^{\text {rd }}$ and $4^{\text {th }}$ mo of treatment this augmented by a significant decrease in serum calcium level in the same mo. Also, there was a significant decrease in serum ALP level from baseline at the $4^{\text {th }}$ mo of treatment, while no significant change occurred in serum PTH throughout the study ( $p>0.05)$.

Table 3: It shows group II (famotidine/(caco ${ }_{3}$ ) group biochemicals throughout the study

\begin{tabular}{llll}
\hline Parameters & Phosphorus level (mg/dl) & Calcium level (mg/dl) & ALP level (mg/dl) \\
\cline { 1 - 2 } Interval & & & PTH level (Pg/ml) \\
\cline { 1 - 2 } & $5.12+0.71$ & $8.79+0.89$ & $90.25+12.36$ \\
$1^{\text {stmo post treatment }}$ & $5.52+0.86$ & $7.65+0.77$ & $85.6+16.2$ \\
$2^{\text {nd }}$ mo post treatment & $6.79+0.91$ & $7.38+0.69$ & $76.29+13.7$ \\
$3^{\text {rd }}$ mo post treatment & $7.43+0.74^{*}$ & $6.24+0.85^{*}$ & $62.21+8.63$ \\
$4^{\text {th }}$ mo post treatment & $7.63+0.69^{*}$ & $6.33+0.71^{*}$ & $155.1+45.6$ \\
\hline
\end{tabular}

* Significant difference from baseline $(p<0.05)$

The biochemicals of group III throughout the study are shown in table 4. Paired student t-test carried out for each parameter between the baseline results and results of each mo post treatment shown a significant decrease in serum ALP level at the $4^{\text {th }}$ mo of treatment no significant changes occurred in other three parameters $(\mathrm{p}>0.05)$.

Table 4: It shows Group III (omeprazole/( $\mathrm{caco}_{3}$ ) group biochemicals throughout the study

\begin{tabular}{lllc}
\hline Parameters & Phosphorus level (mg/d) & Calcium level (mg/dl) & ALP level (mg/dl) \\
\cline { 1 - 3 } Interval & & $9.25+0.69$ & PTH level(Pg/ml) \\
\hline Baseline & $5.05+0.84$ & $8.69+0.58$ & $92.51+16.7$ \\
$1^{\text {st }}$ mo post treatment & $5.16+0.76$ & $7.36+0.91$ & $88.47+16.3$ \\
$2^{\text {nd }}$ mo post treatment & $6+0.94$ & $8.36+0.91$ & $85.44+5.13$ \\
$3^{\text {rd }}$ mo post treatment & $5.15+0.73$ & $8.62+0.74$ & $85.44+5.13$ \\
$4^{\text {th }}$ mo post treatment & $5.15+0.55$ & $188+50.2$ & $136+44.6$ \\
\hline
\end{tabular}

${ }^{*}$ Significant difference from baseline $(p<0.05)$

Serum phosphorus level in the three studied groups compared by ANOVA showed that in $3^{\text {rd }}$ and $4^{\text {th }}$ mo serum phosphorus levels were higher in group II than group I at 3 rd mo $(7.43+0.74)$ versus
$(5.99+0.89)$ with $p=0.039$ and $4^{\text {th }}$ mo $(7.63+0.69)$ versus $(6.03+0.69)$ with $p=0.024$ respectively, with no significant change in group III than group I and group II at baseline and throughout the study. (fig. 1).

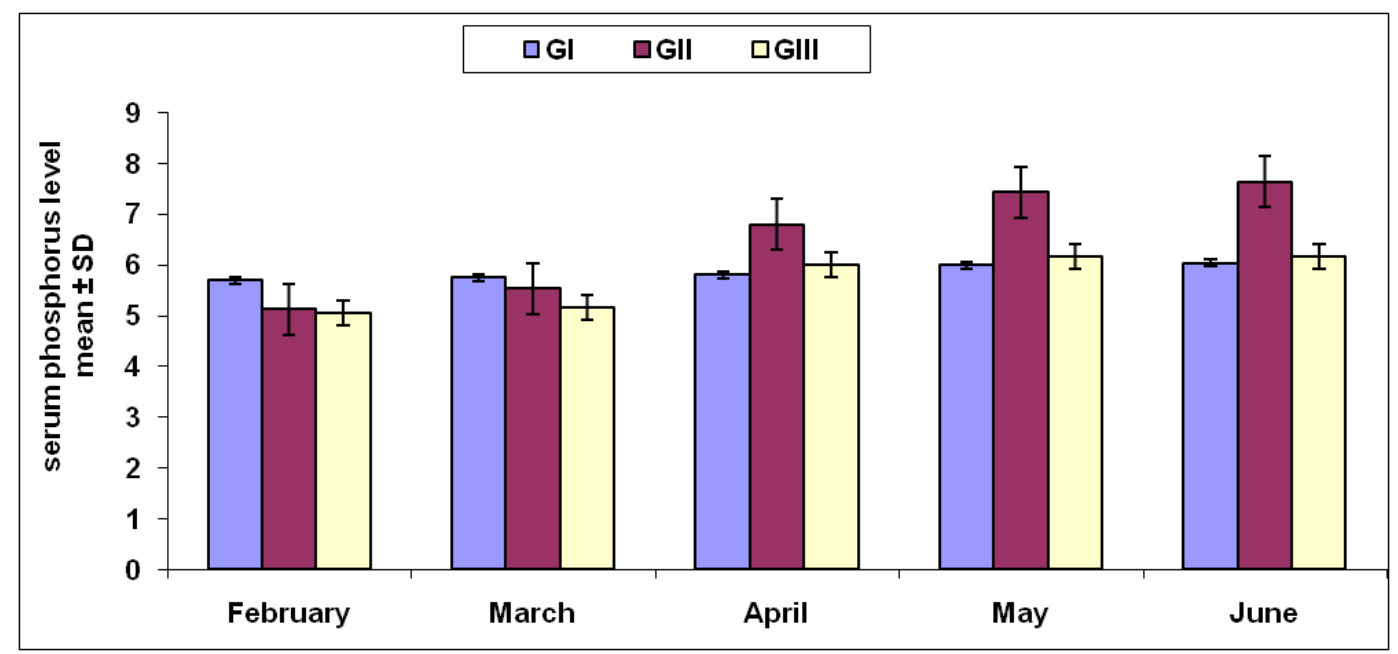

Fig. 1: Shows serum phosphorus level mean+SD value (mg/dl) in 3 studied groups at baseline (February) and each mo along the study

$-N$ in $G I=20, G I I=21$ and GIII = 23, -Significant increase in GII phosphorus compared with GI with no change in GIII

Serum calcium level in the three studied groups compared by ANOVA showed that hyperphosphatemia in group II augmented by the significant decrease in serum calcium level in group II more than group I $(6.24+085)$ versus $(8.31+0.74)$ at $3^{\text {rd }}$ mo post treatment and $(6.33+0.71)$ versus $(7.36+69)$ at $4^{\text {th }}$ mo post treatment with $p$-value 0.039 and 0.024 respectively No significant difference in group III from group I and II along the study.
Serum ALP in the three studied groups compared by ANOVA showed that there was a significant decrease in the ALP level in group II and group III than group I at $4^{\text {th }}$-mo post treatment with $p$ value 0.047 and 0.042 respectively.

Serum PTH in the three studied groups compared by ANOVA showed that there are no significant changes between the three groups along the study $(\mathrm{p}>0.05)$. 
Also, we did clinical questioner to the patients of the three groups to show change in levels of itching as an indication of hyperphosphatemia control while increased level of itching is indication of poor hyperphosphatemia control and from this we showed that group II showed increasing of patients complain of itching from mo to mo comparing to groups I and III. (fig. 2).

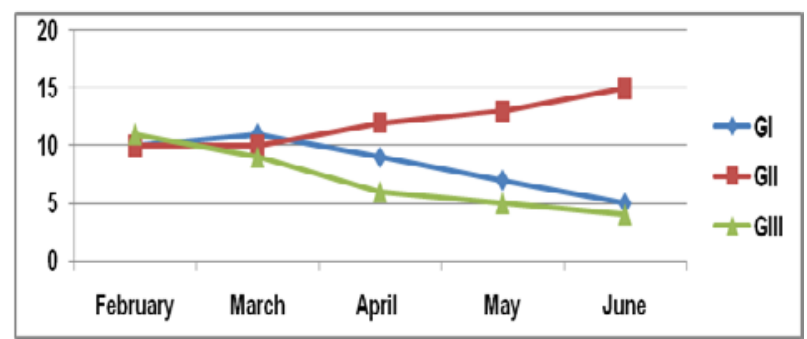

Fig. 2: shows number of patients complained of itching at the baseline mo (February) and then each mo throughout the study

In clinical questioner, we also asked the patients of the three groups about improvement in GIT problem (flatulence, hyperacidity, gastroesophageal reflux, etc) and group III showed a decrease in a number of patients with GIT problems from mo to mo more than group II and group I.

\section{DISCUSSION}

Mineral metabolism derangements occur during the early stages of chronic kidney disease (CKD). Phosphorus serum levels are usually within normal range until the GFR falls below $30 \mathrm{ml} / \mathrm{min}$ according to the National Kidney Foundation Kidney Disease Outcomes Quality Initiative classification.

Although some studies showing the effect of co-administration of either famotidine or omeprazole with $\mathrm{Caco}_{3}$ there is no data compare between both combinations regarding the effect on hyperphosphatemia.

In the present study, it has been found that the regular use of $10 \mathrm{mg}$ once daily of famotidine (the recommended dose for hemodialysis patients) with $\mathrm{Caco}_{3}$ for 4 mo worsens the hyperphosphatemia in chronic renal failure patients on hemodialysis. These data agree with Matsunaga C, et al. who studied the effect of famotidine (10 $\mathrm{mg} / \mathrm{d}$ ) and lansoprazole on serum phosphorus levels in hemodialysis patients on $\mathrm{caco}_{3}$ therapy on 115patients with ESRD in crossover protocol, not parallel [18]

These effects explained by Takahashi et al. they reported that the phosphate binding properties of calcium carbonate depend on gastric acid. Gastric hydrochloric acid increases the solubility of calcium carbonate providing more free calcium ions for binding of phosphate and it is responsible for the partial conversion of calcium carbonate to calcium chloride [19].

In the present study, famotidine aggravated the condition of the patients by augmenting hypocalcaemia state after $4 \mathrm{mo}$. This effect is supported by Goss et al., 2007 who explained that at neutral pH, calcium carbonate is practically insoluble in water, but although the solubility of calcium salts may be highly $\mathrm{pH}$ dependent, calcium absorption is unaffected by alterations in gastric acid secretion [20]

In this study, it has also been found that famotidine with $\mathrm{Caco}_{3}$ did not show any significant change in serum PTH, which contradicted by the study of Bricker, who suggested that original proposal was that phosphate retention as a result of reductions in glomerular filtration rate would cause transient decreases in the levels of calcium, which would, in turn, trigger an increase in PTH secretion and a new steady state would be achieved, with restoration of normal calcium and phosphate levels but, with the consequence that high levels of PTH now would be required to maintain homeostasis [21].
The present study shows a significant decrease in serum ALP level upon administration of famotidine in combination with $\mathrm{CaCO}_{3}$; this is in agreement with Kinjo et al. who reported that long-term use of $\mathrm{H} 2$-receptor antagonists result in a slight reduction in bone mineral density [22]

Regular omeprazole co-administration with $\mathrm{Caco}_{3}$ in the present study produced no significant change in the serum phosphorus level. Hardy et al. reported no significant difference in the control of phosphatemia in 16 patients on chronic hemodialysis [23].

Further support of our study is found in the study of Osler et al. who concluded that omeprazole augmented the phosphate binding capacity of calcium carbonate in six normal subjects [24].

In uremic patients, plasma phosphate levels are dependent on the transmembrane shift of intracellular phosphate toward the extracellular compartment with acidosis and on the plasmatic physicochemical inverse equilibrium of plasma phosphate and calcium beside the intestinal absorption of phosphate.

Our data are contradicting with that of Graziani et al. who found that the stimulating effect of gastric secretion on $\mathrm{Po}_{4}$ intestinal absorption would be due to better solubilization of dietary phosphate for which passive absorption by the duodenum is facilitated in its acid form the rest of the phosphate absorption in its basic form taking place more distally under the control of calcitriol [25].

In group III serum calcium showed no change from control group values. This effect is contradicted by Carr and Shangraw they reported that daily omeprazole increased the median stomach $\mathrm{pH}$ and that the corrected calcemia was significantly lower under omeprazole [26].

The decrease in calcemia with omeprazole had already been observed by Straub, who found that the use of (PPIs) decrease basal and maximal outputs of acid, and will, therefore, diminish the quantity of acid available for the dissociation of calcium salts postprandially [27]. This may be due to the explanation of Yang and Metz. They reported that in the stomach, the systemically absorbed PPIs are delivered to the basolateral surface of the parietal cell. They are weak bases diffuse through the cytoplasm of the cell into the secretory canaliculus. This secretory canaliculus is acidic with a $\mathrm{pH}$ of less than 4.0 such that the weakly basic drug undergoes protonation and is then trapped in this acidic compartment so calcium can be absorbed in the duodenum even in the absence of gastric dissociation because the duodenal brush border locally produces an acid environment [28].

No change in serum PTH level our results which coincide with Hardy et al. [23]. While the results are contradicted by the findings of Mizunashi et al. who suggested that omeprazole treatment is associated with elevated concentrations of PTH in the circulation but, it is not clear whether this resulted directly from gastrinmediated hyperplasia of parathyroid gland [29].

Our data showed a significant decrease in serum ALP level upon combining omeprazole with caco ${ }_{3}$. Hilliard et al. demonstrated that endogenous phosphate interferes with the determination of alkaline phosphates in urine and suggested that the wide variation in serum inorganic phosphate concentrations in diseases such as renal tubular disease or uremia might interfere with alkaline phosphatase measurements in serum [30].

The authors own view for the reason that $\mathrm{Caco}_{3}$ efficacy not affected by co-administration of omeprazole compare to coadministration of famotidine is that omeprazole augmented the phosphate binding capacity of calcium carbonate due to greater intragastric binding of phosphorus by $\mathrm{Caco}_{3}$ even if its dissociation were less because although generated in smaller amounts all the calcium ions would be captured by $\mathrm{Po}_{4}$ because fewer protons would be competing with them for phosphate binding while with famotidine it acts on stomach $\mathrm{H}_{2}$ receptors and not affect protons so, greater protons would be competing with calcium ions for phosphate binding and this effect $\mathrm{CaCO}_{3}$ efficacy. 


\section{CONCLUSION}

Co-administration of famotidine with $\mathrm{Caco}_{3}$ aggravates hyperphosphatemia and this may increase the incidence of complications. The efficacy of calcium carbonate as a phosphate binder was not affected by co-administration of omeprazole.

\section{Study limitation}

The number of our patients was 64 patients only. We used a dose range $(2.5-4 \mathrm{~g} / \mathrm{d})$ for calcium carbonate and to prevent the change in results we used approximate doses between three groups.

\section{ACKNOWLEDGMENT}

We thank the department of renal dialysis members in Tanta University Hospital for their support to study. The authors have no financial interests.

\section{CONFLICT OF INTERESTS}

The authors declare that they have no competing interests.

\section{REFERENCES}

1. Block GA, Klassen PS, Lazarus JM, Ofsthun N, Lowrie EG, Chertow GM. Mineral metabolism, mortality and morbidity in maintenance hemodialysis. J Am Soc Nephrol 2004;15:2208-18.

2. Stavros Patsalas, Theodoros Eleftheriadis, Hariklia Theodoroglou, Georgia Antoniadi, Vassilis Liakopoulos, Vassilis Vargemezis. Coronary artery calcification, coronary artery stenosis and hyperphosphatemia in hemodialysis patients. Ther Apheresis Dialysis J 2007;11:81.

3. Faissal Tarrass, Meryem Benjelloun, Mohamed Zamd, Ghislaine Medkouri, Khahija Hachim, Mohamed Gharbi Benghanem, et al. Heart valve calcifications in patients with end-stage renal disease: analysis for risk factors. APSN J 2006;11:494-6.

4. Terai K, Nara H, Takakura K. Vascular calcification and secondary hyperparathyroidism of severe chronic kidney disease and its relation to serum phosphate and calcium levels. Br J Pharmacol 2009;156:1267-78.

5. Jono S, McKee MD, Murry CE, Shioi A, Nishizawa Y, Mori K. Phosphate regulation of vascular smooth muscle cell calcification. Circ Res 2000;87:10-7.

6. Slatopolsky E, Weerts C, Lopez-Hilker S. Calcium carbonate as a phosphate binder in patients with chronic renal failure undergoing dialysis. N Engl J Med 2005;3:157-61.

7. National Kidney Foundation. K/DOQI clinical practice guidelines for bone metabolism and disease in chronic kidney disease. Am J Kidney Dis 2003;42(4, Suppl 3):1-201.

8. Chong VH, Tan J. Prevalence of gastrointestinal and psychosomatic symptoms among Asian patients undergoing regular hemodialysis. APSN J 2013;18:97-103.

9. Takahashi N, Yuasa S, Hitomi H. Effects of histamine H2receptor antagonists on the phosphorus binding ability of phosphate binders in hemodialysis patients. Jpn J Nephrol 1996;38:610-7.

10. Stern J, Lewis WHP. The colorimetric estimation of calcium in serum with ocresolphthalein complexone. Clin Chem Acta 1957;2:576-80.

11. Sarkar BCR, Chauhan UPS. A new method of determining micro quantities of calcium in biological materials. Anal Biochem 1967;20:155-66.

12. Fiske $\mathrm{CH}$, Subbarow Y. The colorimetric determination of phosphorus. Biol Chem 1925;66:375-400.
13. Goodwin JF. Quantification of serum inorganic phosphorus. Clin Chem 1970;16:776-80.

14. Fujita H. Uber die microbestimmung der bult phosphatase. Biochemistry 1939;30:69.

15. Bowers GN, McCOMBR B. A continuous spectrophotometric method for measuring the activity of serum Alk. phos. Clin Chem 1966;12:70-89.

16. Armitage EK. Parthyrin metabolism and methods for assay Clin Chem 1986;3232:418-24.

17. Kao PC, Grant CS, Klee GG, Khosla S. Clinical performance of parathyroid hormone immunometric assays. Mayo Clin Proc 1992;67:637-45

18. Matsunaga C, Izumi S, Furukubo T, Satoh $\quad M$, Yamakawa T, Uchida T. Effect of famotidine and lansoprazole on serum phosphorus levels in hemodialysis patients on calcium carbonate therapy. Clin Nephrol 2007;68:93-8.

19. Takahashi N, Shoji T, Hirohata M. The effects of histamine H2receptor antagonists on the phosphorus binding ability of calcium carbonate in hemodialysis patients. J Jpn Soc Dial Ther 1999;28:1069-74.

20. Goss S, Lemons KA, Kerstetter JE, Bogner RH. Determination of calcium salt solubility with changes in $\mathrm{pH}$ and $\mathrm{P}$ (CO), simulating varying gastrointestinal environments. J Pharm Pharmacol 2007;59:1485-92.

21. Bricker NS. On the pathogenesis of the uremic state. An exposition of the trade-off hypothesis. $\mathrm{N}$ Engl J Med 2007;286:1093-9.

22. Kinjo M, Setoguchi S, Solomon DH. Antihistamine therapy and bone mineral density: analysis in a population-based US sample. Am J Med 2008;121:1085-91.

23. Hardy P, Hottelart C, Oprisiu R. Role of calcium carbonate administration timing in relation to food intake on its efficiency in controlling hyperphosphatemia in patients on maintenance hemodialysis. Artif Organs 2002;22:564-8.

24. Osler P, Raniga P, Farrington K. Effect of omeprazole on the phosphate-binding capacity of calcium carbonate (letter to the editor). Nephron 1995;69:89-90.

25. Graziani G, Badalamenti S, Como G. Calcium and phosphate plasma levels in dialysis patients after dietary Ca-P overload. The role of gastric acid secretion. Nephron 2002;91:474-9.

26. Carr C, Shangraw R. Nutritional and pharmaceutical aspects of calcium supplementation. Am Pharm 2005;27:49-50, 54-57.

27. Straub DA. Calcium supplementation in clinical practice: a review of forms, doses, and indications. Nutr Clin Pract 2010;22:286-96.

28. YX Yang, DC Metz. Peptic ulcer disease, Diagnosis, and Management. In: Al-Kawas F. ed. Gastrointestinal Diseases: an Endoscopic Approach. $2^{\text {nd }}$ Edn. SLACK Incorporated. USA 2002, Suppl 385-410.

29. Mizunashi K, Furukawa $Y$, Katano K, Abe K. Effect of omeprazole an inhibitor of $\mathrm{H}+/ \mathrm{K}+-\mathrm{ATPase}$, on bone resorption in humans. Calcif Tissue Int 2009;53:21-5.

30. Hilliard SD, O'Donnell JF, Schenker S. On the nature of the inhibitor of urinary alkaline phosphatase. Clin Chem 1998;11:570-4.

\section{How to cite this article}

- Hossam Aboelyazeed, Sahar El-Haggar, Kamal Okasha Comparative study between the effect of histamine receptor antagonists of type II (famotidine) and proton pump inhibitors (omeprazole) on the efficacy of calcium carbonate as phosphate binder in haemodialysis patient. Int J Pharm Pharm Sci 2017;9(8):10-14. 